\title{
Application of Innovative Technologies in the Art Education Lessons
}

\author{
Eleanor Gennadiyevna Butenko \\ Student of the Department of Theory and Methodology of Decorative Arts, \\ graphic arts and graphic faculty of the State institution "South Ukrainian \\ National Pedagogical University named after K. D. Ushinsky"
}

\begin{abstract}
The article reveals the peculiarities of using the rectangular drawing method for developing the creative potential of gifted children. The essence of the method of rectangular drawing is covered. The technique of using the rectangular drawing method for the artistic preparation of children is presented. The mechanisms of development of the creative potential of the child by means of rectangular drawing are revealed and the ways of further researches in this field are outlined.
\end{abstract}

Keywords: right-handed drawing, creative potential, artistic training, brain, exercises.

Introduction. The development of the creative potential of the individual is one of the most urgent tasks of modern society. Accordingly, there is a need to make drastic changes to the content, forms and methods of educational work of young people, in particular students of pedagogical institutions of higher education, where a creative approach to the development of personality, the formation of creative - transforming position, creative potential.

Despite the fact that various innovative processes are being introduced that allow to obtain positive results in the field of children's creative development, innovative technologies of teaching should be used to activate cognitive activities. Problem-solving, communicativelearning technologies, game-learning technologies, technologies, information-communication technologies, project technologies that contribute to an effective learning process aimed at improving the quality of education, developing creative abilities, ability to make decisions independently. Increasingly popular in the modern world are unconventional techniques for developing creative talents. You can learn how to draw in a short time using innovative rectangular drawing techniques.

The degree of elaboration of the problem. The analysis of the scientific literature on the topic of the study suggests that the problem of creative potential formation was considered in the research from the point of view of future teacher's professional training. This contributed to the accumulation of some positive experience in the development of basic theoretical 
provisions on this problem. Thus, the philosophical aspect of creativity was considered in their works by V. Bibler, Y. Boroday, M. Danilov, K. Kedrov, P. Kopshchin, O. Korshunov and others. Psychological and logical foundations of this problem are outlined in the works of D. Bogoyavlenskaya, L. Vygotsky, V. Davydov, D. Elkonin, O. Leontiev, A. Luke, Y. Ponomaryov, S. Rubinstein, and others. The pedagogical aspect of the problem of formation and development of creative activity is considered in the works of V. Andreev, D. Vilkeev, M. Danilov, N. Kichuk, M. Makhmutov, I. Ogorodnikov, N. Polovnikova, I. Rodak, S. Sisoeva, M. Skatkin , T. Shamova, G. Shchukina and others.

Insufficiently lit parts of the problem. At the same time, positively evaluating the achievements of the aforementioned scholars, it should be noted that the problem of forming the creative potential of future teachers is still partially covered. Existing works reveal only some ways to improve student preparation.

The purpose of the article is to reveal the creative potential of the rectangular drawing method for the development of children's creative potential. To justify the position that you can learn how to draw in a short time, using an innovative method of rectangular drawing.

The main content (research methodology). From our own pedagogical experience of recent years, we can note the following negative tendency in the level of general visual literacy of children: creative stiffness, pattern pattern, low level of basic artistic and pictorial abilities: visual memory, artistic and imaginative thinking, spatial representations, imagination.

To enhance cognitive activity, it is necessary to use innovative teaching technologies in the lessons. Problem-solving, communicative-learning technologies, game-learning technologies, technologies, information and communication technologies, project technologies that contribute to an effective learning process, aimed at improving the quality of education, developing students' creative abilities, ability to make their own decisions.

The main content (Discussion). Increasingly popular in the modern world are unconventional techniques for developing creative talents. You can learn how to draw in a short time using innovative rectangular drawing techniques. The popularity of this method is increasing every day. The basis of the method of rectangular drawing is the activation of the right hemisphere of the brain in the mode of creativity. Using special techniques developed by highly skilled specialists, creative activity and intuition of any person are activated. 
Children tend to engage in creative activities, but, as a rule, the education system is formed in such a way that much more time is spent on learning the exact sciences than on creative processes. All this contributes to the stimulation of the left hemisphere, which is known to be responsible for logical processes and analytical thinking. The smooth operation of both hemispheres ensures efficient brain work. The use of methods of right-hemispheric drawing allows to bring harmony to the work of the left and right hemispheres of the brain, which helps to reveal the creative potential of the child. In addition, it helps to protect it from stress and stress, and also helps with the assimilation of the material.

In our opinion, during the exercise of right-handed drawing there is a change in the perception of the world, developing the ability to visualize, break stereotypes. Attitude to life as a creativity is formed and intuitive thinking develops. All these processes occur at the expense of temporary suppression of the left hemisphere and the child, ignoring the logic, transfers to the paper his vision of the subject. Kids just draw what they see without thinking about how to draw properly. Disconnecting logic and rational judgment are the result of such an intuitive method of creativity.

From the history of the problem it follows that the method of "intuitive drawing" was invented and tested in the United States in the 60s of the twentieth century. American teacher Betty Edwards founded a surprisingly effective teaching technique on drawing, and called it "Drawing on the Right Side of the Brain". The Betty Edwards method offers the following possibilities: to perceive light and shadow; perceive space; determine the ratio of objects and their parts; perception of the edges of the object; drawing objects by memory; to draw with the help of imagination [1].

To attract the attention of modern children in the classroom it is necessary to use innovative technologies, non-standard drawing techniques. At Fine Arts classes, I create an atmosphere for children of art therapy, fairytale therapy, and play therapy as an integral part of creativity.

Our method was based on Roger Sperry's concept of functional specialization of the cerebral hemispheres. Since our brain is divided into two hemispheres, it uses two ways of processing information. One hemisphere uses a verbal and analytical mode of thinking - it processes sounds, algo rhythms, mathematical calculations, and language. The other hemisphere uses the figurative mode - size comparisons, color perception, perspectives of 
objects that it sees completely. Subsequently, in Betty's writings, these modes were named "L-mode" and "P-mode", respectively [2].

The essence of the method of rectangular drawing is to temporarily suppress the work of the left hemisphere and transfer the leading role in drawing the right, more suitable for this activity. At work, thoughts from memory of how the object should look like are ignored. Instead, the artist "sees the object in reality" - comparing its size as a whole, the size of the individual elements, the ratio of space, light and shadow, and combining all of this into a single painting.

Intuitive drawing leads to the activation of the right hemisphere, which is responsible for ideas, images, creativity. Whereas in adults, the left is mostly dominant - it is logic, calculation, restriction. On this basis, the method of intuitive drawing is nowadays widely used in the practice of art therapy - it is a great method to avoid internal censorship, to remove emotional blocks and to look at the world and yourself from the other side.

Based on our experience, it follows that the technique and technique of right-handed drawing for children involves the following generalizations. Contour drawing is the first technique of right-handed drawing. The peculiarity of the method is that the picture must be drawn, keeping upside down. And, part of the picture should be closed. Such manipulations will result in images of bars, lines, and color spots. These images must be drawn. The misunderstanding of what is happening will cause the brain to shut off the left hemisphere and right here will be actively involved. And the brain will not even detect logic trying to understand the drawn symbols. And a complete surprise will be a picture that will be an exact copy of what the child was drawing. A huge plus of the lessons of right-handed drawing is the ability to distract children from the computer and TV. Modern children have become dependent on these facilities. Creativity is a very exciting process and can be motivating at any age.

The technique of right-handed drawing involves a set of different exercises that at first glance seem very unusual. It is the originality and incomprehensibility of these exercises that helps to disable logic. Drawing using the right, then left hand, spelling the letter in the mirror allows you to reveal to the children the world of the magic flight of fantasy. 
Drawing in the right-hemisphere mode relieves psychological fatigue, removes internal criticism, increases self-confidence. Children begin to learn better, adults make non-standard decisions and tasks that are not solved in 10 years, are solved. Right-handed technique immerses a person very well in the process of meditation, the state of the Here and Now. It completely abstracts from the external problems of the child, switches attention, relieves psychological stress.

Conclusions. On the basis of the analyzed material it is possible to make certain generalizations and conclusions.

Rectangular drawing for children is a natural activity. The first drawings are more developed in their own way. No matter what comes out and what doesn't, what matters is the process of creativity and the pleasure of leaving a brush or pencil on the paper. Often the baby transfers to the paper not the image of the object, but his perception or feelings associated with it. Drawing in this technique helps: to get rid of the fear of "I can't draw"; relieve tension; go beyond stereotypes; unleash your creative potential; increase selfesteem; reduce anxiety and remove anxiety; to feel confident in their abilities; to feel the world bright and diverse.

Therefore, the use of rectangular drawing means that you can unlock your child's potential for creative imagery. Intuitive drawing techniques help beginners discover themselves and thus enhance self-confidence.

\section{References}

1.Sperri,R.U. (1994) Prospects mentalist revolution. The emergence of a new scientific worldview / R.U. Sperri // Brain and Mind. M.: Nauka. - 269 p.

2. Edwards, B. (2004) Discover the artist // Transl. from English P.A. Samsonov. - 3 ed. Mn .: OOO Potpourri. - $240 \mathrm{p}$.

3. Jarrett L., Lenard L. (2008) Figure. Complete Guide. M.: "Astrel”. - 416 p.

4. Nikolaidis K. (2003) The natural path to drawing // Transl. from English E.L. Kudryavtseva. - Mn .: "Potpourri". - 208 p.

5. Springer S., Deutsch G. (1981) Left brain, right brain. M .: Mir.. - 368 p.

6. Chuprikov A.P., Volkov E.A. (2005) The world of left-handed. K .: "Institute of Neuropsychiatry A. Chuprikov". - 88 p. 